\title{
Aprendizagem como ato de participação: a história de uma comunidade de prática
}

\author{
Ana Silvia Rocha Ipiranga* \\ Ricardo Bezerra de Menezes* \\ José Lindoval Lima Matos *** \\ Gládia Lorena Lima Maia ${ }^{* a+k}$
}

\begin{abstract}
Resumo
Comunidade de prática não é algo novo, mas recentemente tem recebido especial atenção por parte das organizações, mediante 0 incentivo à sua criação e desenvolvimento, como forma de gerir o conhecimento organizacional. Com foco no tópico "segurança da informação", este artigo analisa a história de uma comunidade de prática de um banco federal. A aprendizagem é vista de uma perspectiva social que remete à interação, troca de experiências e diálogo. Dessa forma, as evidências empíricas do trabalho da comunidade de prática foram conseguidas através da narração de histórias de seus membros. Os dados foram coletados mediante entrevista temática e interpretados a partir da articulação de um instrumento de análise da narrativa. Pelo conflito que se estabeleceu na história da comunidade de prática examinada, é sugerido o suporte da empresa à sua dispersão. Portanto, o caso suscita questões a serem mais amplamente refletidas em estudos de outras comunidades.
\end{abstract}

Palavras- chave: comunidades de prática; organizações de aprendizagem; narração de histórias.

\begin{abstract}
Although Community of Practice (COP) is not a novel subject, it has recently demanded special attention from organizations, which have been encouraging its creation and development aiming organizational knowledge. In this context, this contribution assesses the history of a CoP located at a federal bank, focusing on the Information Security subject. Considering that this research shares the knowledge of learning in a social perspective that refers to phenomena such as interaction, exchange of experiences and dialogue, empirical evidences of the CoP's work were obtained by means of its members' history narrative. A thematic interview was performed to collect data. Since a conflicting circumstance was observed in the examined CoP's history, it is suggested that the company should support its dispersion. The present case study evokes questions that should be addressed in a more detailed manner concerning the study of other communities.
\end{abstract}

Key words: community of practise, organizational learning, history narrative

\section{Introdução}

Na década de 1990 o termo "conhecimento" foi definitivamente incorporado ao meio empresarial, em decorrência da preocupação sobre como utilizar esse ativo para o sucesso e a estratégia do negócio. Por outro lado, o meio acadêmico tem procurado fomentar pesquisas científicas nessa área, buscando uma maior aproximação com a prática organizacional.

* Doutora em Psicologia do Trabalho e da Organização. Professora da Universidade Estadual do Ceará (UECE). E-mail: anasilviaipi@ uol.com.br. Endereço: Av. Abolição 2480 / 1004 - Meireles - Fortaleza - CE - CEP 60165080.

** M estre em Administração de Empresas. Professor da Faculdades para o Desenvolvimento Humano. E-mail: ricardo.menezes@ gmail.com. Endereço: Rua Dr. Zamenhof, 400 / 401 - Bairro Cocó - Fortaleza - CE - CEP 60176-060.

*** Mestre em Administração de Empresas. Professor da Faculdades para o Desenvolvimento Humano. E-mail: jlaragao@ bnb.gov.br. Endereço: Rua Conselheiro Tristão, 373 / 703 - Bairro José Bonifácio - Fortaleza - CE - CEP 60050-100.

* Mestre em Adminstração de Empresas pela Universidade de Fortaleza - UNIFOR. Professora da Faculdade Christus (Fortaleza - CE) e da Faculdade Católica Rainha do Sertão (Quixadá - CE). E-mail: gladiamaia@ uol.com.br. Endereço: Rua Visconde de Mauá, 2555, ap. 1502 - Bairro Dionísio Torres - Fortaleza - CE CEP 60125-161.

Artigo recebido em fevereiro de 2005 e aceito para publicação em março de 2005. 
A lógica que traduz o conhecimento como recurso estratégico - que ganha vigor ao ser compartilhado parece ter sido compreendida por boa parte das organizações, causando um rearranjo nos modelos básicos de negócios. Dessa perspectiva, novas formas de gerir o conhecimento, compartilhá-lo e convertê-lo em favor da estratégia do negócio têm surgido no dia-a-dia empresarial.

A idéia de que a aprendizagem é um fenômeno social e vem, em lato sensu, da experiência da vida cotidiana tem ganhado base significativa em anos recentes. Foi esse pensamento que constituiu a base de um importante repensar da teoria da aprendizagem - no final dos anos 1980 e início dos anos 1990 - por dois pesquisadores, Jean Lave e Etienne Wenger, cujo modelo de aprendizagem propunha que esta envolveria um engajamento em comunidade de prática.

O termo comunidade de prática (em inglês, community of practice, ou, simplesmente, CoP) foi cunhado e definido como "grupos de pessoas que compartilham uma preocupação, um conjunto de problemas ou uma paixão por um tópico, e que aprofundam seu conhecimento e especialização nessa área pela interação numa base continuada" (LAVE e WENGER, 1991). Os autores entendem que as comunidades de prática estão por toda parte e que, geralmente, as pessoas estão envolvidas numa grande quantidade delas - quer seja no trabalho, na escola, em casa ou em outras situações, como no lazer. Em alguns grupos, o indivíduo é membro do núcleo da comunidade; em outros, está mais à margem dela.

O aprendizado ganha contornos sociais, renunciando, em parte, à idéia da aprendizagem centrada em processos cognitivos, em prol de uma perspectiva mais focada nas práticas sociais.

Wenger (1998) resume a perspectiva social da aprendizagem nos seguintes princípios:

- a aprendizagem é inerente à natureza humana;

- consiste na primeira e principal habilidade para negociar novos significados;

- é, fundamentalmente, experimental e social;

- transforma identidades e constrói trajetórias de participação;

- significa lidar com fronteiras;

- é uma questão de energia social, poder, alinhamento e engajamento;

- envolve uma ação recíproca entre o local e o global.

Nesse sentido, o conhecimento se coloca como indissociável das comunidades que o criam, usam e transformam. Em todos os tipos de trabalho de conhecimento- até mesmo naqueles em que a tecnologia tem papel vital - as pessoas requerem conversação, experimentação e experiências compartilhadas com outras envolvidas nas mesmas atividades. Especialmente, ao irem além dos processos rotineiros para enfrentar desafios mais complexos, elas acreditam, fortemente, na sua comunidade de prática como fonte primordial de conhecimento.

Este artigo - fundamentado em argumentos da aprendizagem organizacional - visa à análise experiencial de uma comunidade de prática, com foco na "segurança da informação". Busca relacioná-la com o repertório teórico, a partir das evidências de sua formação, organização, dimensões, objetivos, estágios de desenvolvimento, níveis de participação e dos resultados para a organização. A análise considera, ainda, o que a organização poderia fazer não só para potencializar e capitalizar os ganhos da comunidade de prática eleita para o estudo, mas também para estimular e apoiar o surgimento e a evolução de novas comunidades. Nesse sentido, foi adotada a abordagem qualitativa para o desenvolvimento metodológico da pesquisa. O estudo de caso, em um banco federal, é legitimado, na medida em que "examina um fenômeno contemporâneo dentro de seu contexto" (YIN, 1994). 
Estabelecido esse objetivo e procurando manter a estreita relação entre abordagem teórico-metodológica e pressuposto epistemológico de caráter fenomenológico, recorreu-se à técnica da narração de histórias considerada como "vida de experiência do mundo" (ROSENTHAL, 2000). Nesse sentido, buscou-se evidências empíricas do trabalho da comunidade de prática por meio da narração de histórias de seus membros (EASTERBY-SMITH e ARAÚJO, 2001), articulando-se um instrumento de análise dessa narrativa.

O artigo está estruturado em seções que tratam dos seguintes tópicos: revisão da literatura de suporte à investigação, metodologia da pesquisa e descrição de caso através das narrativas. A última seção traz as conclusões da pesquisa.

\section{Comunidades de prática}

\section{Contextualização}

Com as novas tecnologias de informação e comunicação, as redes sociais têm se tornado comuns dentro e fora das organizações. Entretanto, para sua sobrevivência, uma organização precisa mais do que de redes sociais; necessita ser autógena. Atualmente, os teóricos organizacionais empregam o termo "comunidades de prática" para denominar essas redes sociais autógenas (CAPRA, 2004).

Dependendo do seu grau de maturação e sofisticação, as redes informais que surgem e se desenvolvem em meio às estruturas formais, chamadas de comunidades de prática, mais ajudarão a organização a aprender, responder criativamente a novas circunstâncias, mudar e se desenvolver.

É perceptível que as estruturas organizacionais formais podem facilitar a alocação de recursos, a tomada de importantes decisões e o alinhamento de obrigações, mas parecem insuficientes para o desenvolvimento e para a aplicação e disseminação de conhecimento. As arquiteturas informais (infere-se) seriam muito mais propícias à aprendizagem e ao desenvolvimento de novos conhecimentos.

Pelo fato de que a aprendizagem é tão diretamente parte da prática, esta não é percebida como aprendizagem. Como resultado, a prática é, geralmente, concebida como estática, senão caótica, desestruturada e, desse modo, aleatoriamente adaptada. $\mathrm{O}$ que muitos não percebem é que a prática tem uma lógica própria, não seguindo o curso da lógica linear tradicional (WENGER, 1998).

Esta é a aprendizagem que ocorre em intervalos da vida organizacional - no café ou durante uma saída de carro, numa reunião à beira de uma piscina ou durante um processo de produção no chão-de-fábrica (ANTONELLO e RUAS, 2002).

Para Wenger (1998), o conceito de prática não implica dicotomia entre prática e teoria; podendo a comunidade de prática ser definida como um contexto ou local onde se desenvolve, se negocia e se compartilha o modo de viver (n)o mundo. Viver, conforme essa conceituação, é um processo contínuo de negociação de significados. Até mesmo quando comunidades se especializam em produzir teorias também é uma prática (ROCHA, 2001).

Uma comunidade de prática envolve muito mais do que o conhecimento técnico ou habilidade associada à obrigação de alguma tarefa. Os membros estão enredados num conjunto de relacionamentos ao longo do tempo (LAVE e WENGER, 1991) e comunidades se desenvolvem ao redor de coisas que interessam às pessoas (WENGER, 1998). O fato delas estarem organizadas em torno de alguma área de conhecimento e atividade em particular dá aos seus membros um senso de iniciativa conjunta e de identidade. Para uma comunidade de prática funcionar, ela precisa gerar e apropriar-se de um repertório de idéias, compromissos e lembranças compartilhados. Ela também precisa desenvolver vários recursos, tais como ferramentas, documentos, rotinas, vocabulário e símbolos que de algum modo conduzem o conhecimento acumulado pela 
comunidade. Em outras palavras, tal iniciativa envolve prática e formas de fazer e abordar coisas que são compartilhadas para alguma extensão significativa entre os membros.

Nas comunidades de prática as pessoas são movidas por um senso de propósito e por uma necessidade de conhecer o que os outros sabem, sendo definidas pelo conhecimento que geram, em vez da tarefa, característica que as distingue das equipes de trabalho. Além disso, a perenidade de uma comunidade é definida pelo valor que ela cria para seus membros e não pela conclusão de um projeto predeterminado.

O quadro 1 reúne e permite confrontar as principais características de diferentes estruturas associativas que podem surgir nas organizações.

Quadro 1 - Comparação resumida das estruturas associativas nas organizações

\begin{tabular}{|c|c|c|c|c|}
\hline & OBJETIVO & PARTICIPANTES & AFINIDADES & DURAÇÃO \\
\hline $\begin{array}{l}\text { COMUNIDADE } \\
\text { DE PRÁTICA }\end{array}$ & $\begin{array}{l}\text { Desenvolver as } \\
\text { competências dos } \\
\text { participantes, gerar } \\
\text { e trocar } \\
\text { conhecimentos }\end{array}$ & $\begin{array}{l}\text { Participantes que se } \\
\text { auto-selecionam }\end{array}$ & $\begin{array}{l}\text { Paixão, } \\
\text { compromisso e } \\
\text { identificação com } \\
\text { os conhecimentos } \\
\text { especializados do } \\
\text { grupo }\end{array}$ & $\begin{array}{l}\text { Enquanto houver } \\
\text { interesse em } \\
\text { manter o grupo }\end{array}$ \\
\hline $\begin{array}{l}\text { GRUPO DE } \\
\text { TRABAHO } \\
\text { FORMAL }\end{array}$ & $\begin{array}{l}\text { Desenvolver um } \\
\text { produto ou prestar } \\
\text { um serviço }\end{array}$ & $\begin{array}{l}\text { Qualquer um que se } \\
\text { apresente ao gerente } \\
\text { do grupo }\end{array}$ & $\begin{array}{l}\text { Requisitos do } \\
\text { trabalho e metas } \\
\text { comuns }\end{array}$ & $\begin{array}{l}\text { Até a próxima } \\
\text { reorganização }\end{array}$ \\
\hline $\begin{array}{l}\text { EQUIPE DE } \\
\text { PROJETO }\end{array}$ & $\begin{array}{l}\text { Realizar } \\
\text { determinada tarefa }\end{array}$ & $\begin{array}{l}\text { Empregados } \\
\text { escolhidos por } \\
\text { gerentes seniores }\end{array}$ & $\begin{array}{l}\text { As metas e pontos } \\
\text { importantes do } \\
\text { projeto }\end{array}$ & $\begin{array}{l}\text { Até o final do } \\
\text { projeto }\end{array}$ \\
\hline $\begin{array}{l}\text { REDE } \\
\text { INFORMAL }\end{array}$ & $\begin{array}{l}\text { Colher e transmitir } \\
\text { informações } \\
\text { empresariais }\end{array}$ & $\begin{array}{l}\text { Amigos e } \\
\text { conhecimentos do } \\
\text { meio empresarial }\end{array}$ & $\begin{array}{l}\text { Necessidades } \\
\text { mútuas }\end{array}$ & $\begin{array}{l}\text { Enquanto as } \\
\text { pessoas tiverem um } \\
\text { motivo para } \\
\text { manterem contato }\end{array}$ \\
\hline
\end{tabular}

Fonte: adaptado, pelos autores, a partir de Wenger e Snyder (2001)

Nas equipes de trabalho e de projetos, as metas são determinadas pelo gerente ou coordenador; enquanto na comunidade são negociadas entre seus membros. Cabe também ao líder das equipes de trabalho a escolha dos membros que desenvolverão o projeto; enquanto nas comunidades de prática, os componentes se autoselecionam. Por fim, cumpre destacar que as redes informais têm como objetivo coletar e passar informações, inexistindo, como ocorre nas comunidades de prática, iniciativas conjuntas - tais como o desenvolvimento compartilhado de ferramentas - que as mantenham unidas. As redes informais são, em essência, um conjunto de relacionamentos, o que, por si, não as tornam uma comunidade de prática. É exigido das comunidades um senso de missão, pois há algo que as pessoas querem concluir ou construir juntas e que nasce de seu repertório compartilhado.

O espaço social das comunidades surge entre equipes de projetos e redes de conhecimento. Quando múltiplas equipes de projeto estão engajadas em tarefas similares, a necessidade de compartilhar o que sabem levará, certamente, à formação da comunidade. Por outro lado, uma rede de conhecimento de pessoas que compartilham interesses comuns, organizada de forma livre, pode consolidar-se numa comunidade focada quando as pessoas reconhecerem novas oportunidades compartilhadas.

Hoje em dia, com a mobilidade progressiva da força de trabalho, as pessoas estão, amiúde, mais alinhadas à sua identidade profissional do que à afiliação organizacional. Por isso, empresas que associam, ativamente, novos desafios à prática de comunidades descobrem que os níveis de retenção de talentos aumentam bastante. Além disso, muitas pessoas também participam em comunidades de práticas externas, local e globalmente, servindo como "sinapses" inteligentes que interagem tanto com o sistema social mais amplo, 
quanto com a empresa. Atualmente, muitas entidades que trabalham para o sucesso da empresa não estão dentro dela. São clientes, fornecedores, parceiros comerciais, trabalhadores contratados ou consultores que, freqüentemente, participam em comunidades de aprendizagem que ampliam, interna e externamente, as fronteiras organizacionais.

Outra forma de definir uma comunidade de prática é estabelecer o que ela não é. Não se trata de um conjunto de ferramentas eletrônicas utilizadas para compartilhar informações. Pelo contrário, uma comunidade de prática é um grupo de pessoas que constroem um relacionamento informal em torno de um tópico ou de um assunto em particular. Geralmente, essas pessoas estão geograficamente dispersas, inexistindo diferenciação hierárquica e um líder formal ou explicitamente nomeado. Os relacionamentos informais que elas constituem são estabelecidos, normalmente, para resolver ou encaminhar um problema ou questão, o que ocorre através de uma série de comunicações e/ou colaborações que se efetivam por vários meios.

A comunidade de prática compreende um grupo de indivíduos que trabalham juntos durante um longo período e que, por terem compartilhado práticas, também compartilham experiências ricas. Além disso, elaboram seus próprios mecanismos de confiança, porque sabem o que cada um deles é capaz de fazer. Isso permite que, dentro da comunidade, as idéias fluam mais facilmente (BROWN e DUGUID, 2000).

Com o objetivo de acentuar as distinções entre diversas estruturas organizacionais e delimitar o conceito de comunidades de prática, Wenger (1999) descreve três importantes dimensões dessas comunidades:

- domínio - as pessoas se organizam em torno do domínio de conhecimento que lhe dê um sentido de iniciativa conjunta e as mantenha unidas;

- comunidade - as pessoas funcionam como uma comunidade, mediante relacionamentos de confiança e engajamento mútuo que atam fortemente o grupo numa entidade social; $\mathrm{e}$

- prática - as pessoas se capacitam na sua prática de desenvolvimento de um repertório e pelo compartilhamento de recursos - tais como ferramentas, documentos, rotinas, vocabulários, símbolos e artefatos - que incorporam o conhecimento acumulado pela comunidade. Esse repertório fundamenta futuras aprendizagens.

\section{Estágios de desenvolvimento}

As comunidades de prática trespassam os cinco estágios de desenvolvimento representados na figura 1: 
Figura 1 - Estágios típicos de desenvolvimento de uma comunidade de prática

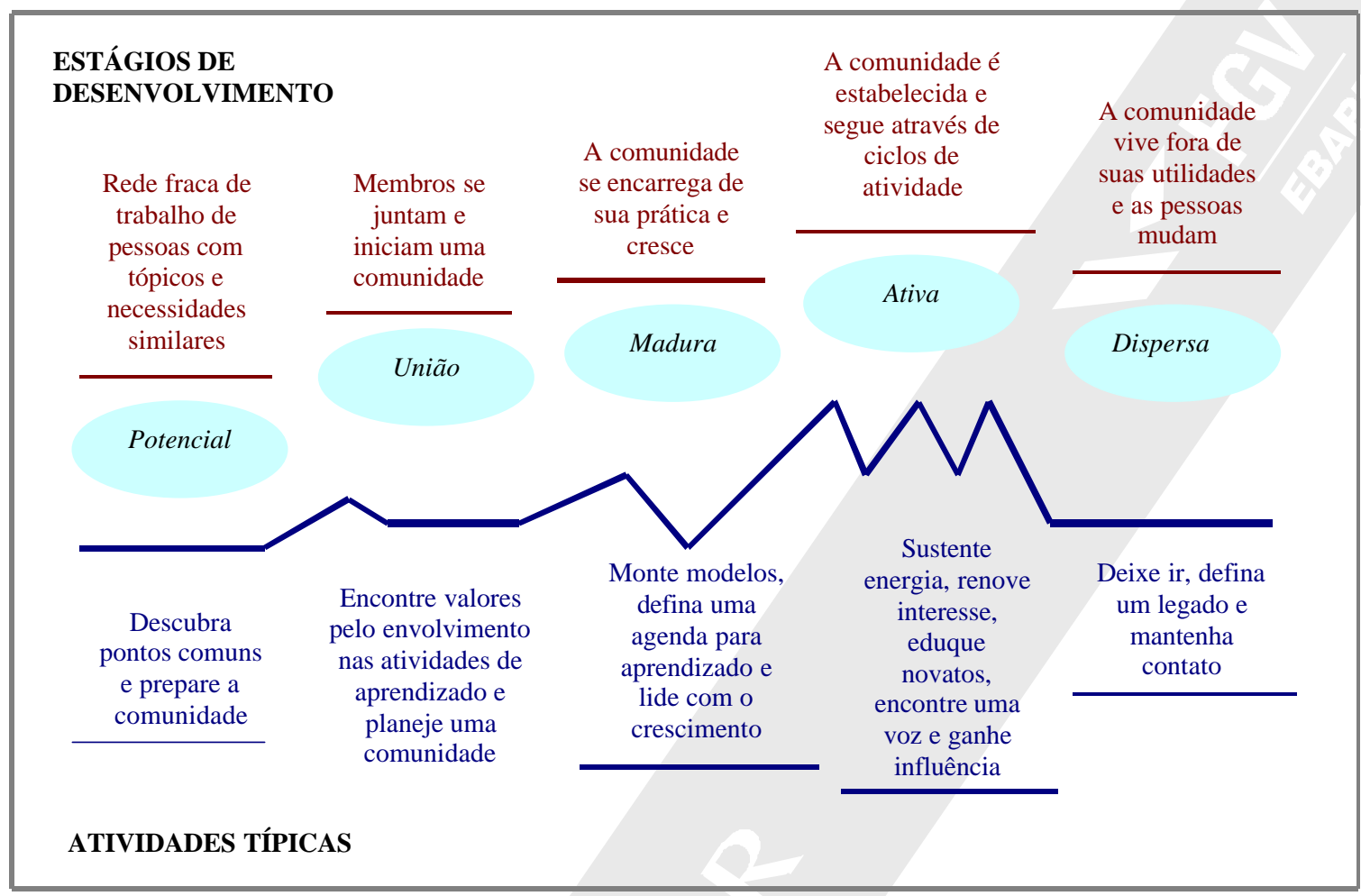

Fonte: Wenger (1999)

No primeiro estágio (potencial), há uma rede imprecisa de pessoas com questões e necessidades similares. As pessoas precisam se encontrar, descobrirem uma causa comum e se preparar para uma comunidade.

O segundo estágio (união) ocorre quando as pessoas se reúnem e lançam uma comunidade. As pessoas buscam valor no engajamento em atividades de aprendizagem.

A comunidade de prática passa, então, ao terceiro estágio, caracterizado pela maturidade. A comunidade assume a responsabilidade de sua prática e cresce. Os membros ajustam padrões e definem uma agenda de aprendizagem. Nesse momento, eles estão se engajando nas atividades conjuntas, criando artefatos e desenvolvendo compromissos e relacionamentos.

No quarto estágio (ativa), a comunidade está estabelecida e avança por ciclos de atividades. Os membros precisam de meios para sustentar energia, renovar interesses, educar novatos, encontrar uma voz e ganhar influência.

Por fim, há o quinto estágio, quando a comunidade se dispersa por viver fora de sua utilidade, provocando mudanças nas pessoas. Nesse momento, as organizações devem deixar que as pessoas se distanciem, embora mantendo contato com elas e definindo um legado.

\section{Níveis de participação}

Os relacionamentos nas comunidades são estabelecidos pela negociação de significados, levando a diferentes graus de participação e definindo a identidade dessas comunidades. Os diversos graus de participação decorrem do fato de que os membros têm necessidades, interesses e perspectivas diferentes. Essa categorização pressupõe flexibilidade - de uma participação no grupo principal até uma participação de acesso passivo -; sendo esses graus de participação definidos por Wenger (1999) como: 
- grupo principal - um grupo pequeno de pessoas cuja paixão e envolvimento energiza a comunidade de prática;

- participação completa (membro total) - indivíduo reconhecido como praticante e que define a comunidade;

- participação periférica - pessoa que pertence à comunidade, mas com grau menor de envolvimento, tanto por ainda ser considerada novata, como por não ter muito compromisso pessoal com a prática;

- participação transacional (ou ocasional) - pessoa de fora da comunidade que, ocasionalmente, interage com ela, visando receber ou fornecer serviços. Não é, necessariamente, membro da comunidade;

- acesso passivo - uma ampla diversidade de pessoas com acesso aos artefatos produzidos pela comunidade, como, por exemplo, suas publicações, seus sites na web ou suas ferramentas.

$\mathrm{Na}$ comunidade, um novato aprende com veteranos quando tem a permissão de participar de certas tarefas que se relacionam com a prática. Com o tempo, o novato se move da participação periférica para a participação completa. "Periferalidade" não é um conceito físico, na medida em que central e periférico não são uma simples medida da quantidade de conhecimento que se adquiriu. Os termos participação periférica e participação completa são usados para denotar o grau de engajamento e participação na comunidade (LAVE e WENGER, 1991).

A participação possibilita entender as comunidades de prática, as quais, não implicam, necessariamente, copresença, fronteiras socialmente visíveis ou um grupo bem definido ou identificável. Implicam atividade na qual os participantes têm um entendimento comum sobre o que ela é e o que significa para suas vidas e a comunidade. A comunidade e o grau de participação na mesma são inseparáveis da prática (LAVE e WENGER, 1991).

Por sua vez, as comunidades de prática podem ser caracterizadas por apresentarem as seguintes dimensões:

- empreendimento conjunto;

- envolvimento mútuo; e

- repertório compartilhado pelos seus membros sobre o modo de realizar as atividades, no qual os recursos são comuns, sejam rotinas, sensibilidade, artefatos, vocabulário e estilos (WENGER, 1999).

As comunidades de prática caracterizam contextos sociohistóricos onde ocorre o aprendizado social pela negociação de significados, da participação e da reificação, esta definida como o processo em que é dado forma às experiências pessoais através da produção de objetos que congelam tal experiência em "coisas" (WENGER, 1998).

Para Wenger (1998), a prática reside numa comunidade de pessoas e nas relações de engajamento mútuo. Os membros de uma comunidade de prática trabalham juntos, zelam uns pelos outros, conversam entre si, trocam informações e opiniões; sendo, de modo rotineiro, diretamente influenciados pelo entendimento mútuo. O mesmo autor demonstra que o desenvolvimento da prática leva algum tempo, mas o que define uma comunidade de prática em sua dimensão temporal não é apenas uma questão de "quanto tempo", mas a sustentação do engajamento na busca de um empreendimento mútuo que compartilhe um aprendizado significativo.

Depreende-se daí que comunidades de prática podem ser pensadas a partir de histórias compartilhadas de aprendizagem; e, para que a prática nessas comunidades seja um processo intencional, seus membros realizam tarefas conjuntas, negociam novos significados e aprendem uns com os outros, compartilhando suas competências com as novas gerações. 


\section{Criação e desenvolvimento de uma comunidade de prática}

Hoje, o grande desafio para as organizações é fortalecer o desenvolvimento das comunidades de prática dentro de suas estruturas formais e rígidas. Uma das saídas diante desse desafio é que estruturas formais provejam o ambiente e os recursos para o suporte das comunidades. A partir dá, gerir o conhecimento organizacional torna-se responsabilidade das comunidades, inexistindo regras formais, prazos ou manipulações.

Wenger (1999) alerta que as empresas devem estimular comunidades de aprendizagem, incentivando processos de reflexão e o acesso a informações, como parte da própria prática. Uma vez que se disponha das necessárias condições- entendimento do contexto e das circunstâncias, acesso a recursos e controle sobre seu destino - as comunidades de prática podem usar sua história compartilhada como um recurso social para a rápida aprendizagem.

A emergência das comunidades de prática vem sendo tolhida pela falta de entendimento e de comprometimento por parte das lideranças das organizações. A par (e em decorrência) disso, essas lideranças não têm feito uma avaliação do potencial dessas comunidades, muito menos criado um ambiente favorável ao seu florescimento.

O remédio para isso não é difícil: algumas alterações na estrutura, que removam algumas barreiras, e pequenos investimentos em recursos que auxiliem na sua implantação e formulação. Além disso, seria necessário algum tempo dos líderes, para acompanhamento e evolução dessas comunidades (McMASTER, 2004).

A sua natureza informal e as possibilidades da moderna tecnologia da informação facilitam a formação das comunidades de prática. Uma das dificuldades em organizações formais, que pode ser superada, é entender que o formal, geralmente, matará iniciativas que queiram acontecer naturalmente. $\mathrm{O}$ formal deve encontrar o meio mais apropriado de refrear muitas de suas práticas habituais de gestão e apoiar essas comunidades.

Wenger (1999) entende que as comunidades de prática podem ser identificadas e, a partir daí, criadas, nutridas e desenvolvidas, desde que as organizações garantam as condições necessárias para isso. As organizações não devem tentar controlar as comunidades de prática, nem lhes atribuir responsabilidades de negócio, guardando para si somente o encargo de ajudar na resolução dos problemas.

Em síntese, Terra e Gordon (2002) avaliam como as organizações podem estimular o desenvolvimento de uma comunidade de prática:

- fornecendo recursos (conteúdos, tempo e dinheiro) para que pessoas que estejam fisicamente distantes entre si possam se encontrar;

- aceitando sua legitimidade informal;

- promovendo e compartilhando os resultados práticos alcançados por tais comunidades de prática;

- comunicando que tipo de atividade é bem-vinda, institucionalizando as redes (formais ou informais) na escala de valores da organização;

- valorizando a participação e a iniciativa individual;

- criando uma infra-estrutura que facilite a comunicação entre os membros; e

- apoiando a criação de novos papéis voltados, exclusivamente, para a promoção e a manutenção dessas iniciativas (os moderadores de conhecimento). 


\section{Benefícios de uma comunidade de prática}

São diversos os benefícios que uma comunidade de prática traz para o indivíduo, para o negócio e para a própria comunidade (quadro 2), como meios eficazes de compartilhamento de conhecimento e "alavancadores" das metas organizacionais.

Quadro 2 - Benefícios de uma comunidade de prática

\begin{tabular}{|c|c|c|}
\hline $\begin{array}{l}\text { BENEFÍCIOS PARA O } \\
\text { NEGÓCIO }\end{array}$ & $\begin{array}{l}\text { BENEFICIOS PARA A } \\
\text { COMUNIDADE }\end{array}$ & $\begin{array}{l}\text { BENEFÍCIOS PARA O } \\
\text { INDIVÍDUO }\end{array}$ \\
\hline ajuda a dirigir a estratégia & $\begin{array}{l}\text { ajuda a construir linguagem, } \\
\text { métodos e modelos comuns em } \\
\text { torno de competências específicas }\end{array}$ & ajuda na realização do trabalho \\
\hline $\begin{array}{l}\text { propicia mais rápida solução de } \\
\text { problemas, localmente e na } \\
\text { organização como um todo }\end{array}$ & $\begin{array}{l}\text { proporciona conhecimento e } \\
\text { expertise a um maior número de } \\
\text { pessoas }\end{array}$ & $\begin{array}{l}\text { confere um sentido estável de } \\
\text { comunidade diante dos colegas e da } \\
\text { empresa }\end{array}$ \\
\hline $\begin{array}{l}\text { ajuda no desenvolvimento, } \\
\text { recrutamento e retenção de talentos }\end{array}$ & $\begin{array}{l}\text { ajuda a reter conhecimento quando } \\
\text { empregados deixam a empresa }\end{array}$ & $\begin{array}{l}\text { estimula senso de identidade com } \\
\text { foco na aprendizagem }\end{array}$ \\
\hline $\begin{array}{l}\text { constrói capacidades essenciais e } \\
\text { competências de conhecimento }\end{array}$ & $\begin{array}{l}\text { aumenta o acesso à expertise através } \\
\text { da empresa }\end{array}$ & $\begin{array}{l}\text { ajuda a desenvolver habilidades e } \\
\text { competências individuais }\end{array}$ \\
\hline $\begin{array}{l}\text { difunde, mais rapidamente, práticas } \\
\text { para excelência operacional }\end{array}$ & $\begin{array}{l}\text { fornece meio de compartilhar poder } \\
\text { e influência com as partes formais } \\
\text { da organização }\end{array}$ & $\begin{array}{l}\text { ajuda o trabalhador do } \\
\text { conhecimento a permanecer } \\
\text { atualizado }\end{array}$ \\
\hline $\begin{array}{l}\text { possibilita gerar idéias e ampliar } \\
\text { oportunidades de inovação }\end{array}$ & & $\begin{array}{l}\text { propicia desafios e chances de } \\
\text { contribuição }\end{array}$ \\
\hline
\end{tabular}

Fonte: adaptado, pelos autores, a partir de Allee (2000).

\section{Procedimentos metodológicos}

Para o desenvolvimento metodológico desta pesquisa foi adotada a abordagem qualitativa. Considerando a aprendizagem de uma perspectiva social que remete a fenômenos como interação, troca de experiências e diálogo, procurou-se evidências empíricas do trabalho da comunidade de prática através da narração de histórias de seus membros (EASTERBY-SMITH e ARAÚJO, 2001).

O estudo visa descrever e analisar a comunidade, valorizando as histórias ouvidas, que permitem "esclarecer as relações complexas entre atividades, conhecimentos e desempenho" (WENGER e SNYDER, 2001). Há crescente interesse na utilização de métodos narrativos e lingüísticos quando o assunto investigado é, particularmente, a aprendizagem organizacional. Tais métodos se efetivam por meio da linguagem, da narração de histórias e das conversações (SIMS, 2001). Nesse sentido, pode-se dizer que a aprendizagem organizacional é construída pela narração de histórias. Essa premissa se baseia no fato de que o contador de história ou o "tecelão da narrativa" (SIMS, 2001, p.67) compartilha a sua melhor prática, revelando êxitos ou aquilo que precisa ser modificado.

Em relação ao escopo, a pesquisa é classificada como estudo de caso, considerando que se ateve a uma única comunidade existente na empresa onde foi realizado a pesquisa. No estudo de caso, os instrumentos de coleta de dados podem ser diversificados, dando flexibilidade à análise dessas informações (YIN, 1994). Assim, foram feitas entrevistas temáticas, separadamente, com cada um dos seis membros que formavam o núcleo da comunidade de prática. Optou-se pela entrevista temática, porquanto os temas têm estatuto relativamente definidos na trajetória de vida desses depoentes, haja vista a função que desempenham e seu envolvimento e experiência em acontecimentos da história da comunidade de prática (ALBERTI, 1989). Os temas abordados nas entrevistas foram estabelecidos a partir das categorias teóricas articuladas anteriormente, refletindo, sobretudo, os objetivos deste estudo. 


\section{0 caso: as histórias narradas}

Foi analisada uma comunidade de prática constituída por um grupo multidisciplinar de profissionais de um banco federal vindos de duas áreas: tecnologia da informação (TI) e auditoria. A comunidade foi escolhida para exame por apresentar algumas das características referidas na teoria que fundamenta este artigo, como a informalidade, o interesse comum, preocupação em solucionar um problema, engajamento mútuo, busca de aprendizado, repertório comum e compartilhamento de conhecimento. A segurança da informação era o tema de interesse da comunidade de prática.

Para Rosenthal (2000), a reconstrução da uma história exige um procedimento analítico que se segue à acumulação sequiencial do texto. Considerando que as narrativas são um tipo particular de organização de enunciados, ou ainda, "representações de ações" (ADAM e REVAZ, 1997), os acontecimentos relatados nas entrevistas foram transformados em histórias através de uma operação que reuniu um conjunto de ações num todo significante, construindo assim um corpus organizado conforme a seguinte seqüência narrativa:

- situação atual - define o tema e apresenta os constituintes, personagens, circunstâncias e componentes;

- nó desencadeador - afiguram-se os fatos e os motivos que determinam o desenrolar da história;

- ação - é a arquitetura do enredo, a trama, o mosaico de ações e reações dos personagens e as avaliações dos acontecimentos;

- desenlace - delineia os elementos determinantes do êxito ou da solução do problema que é colocado; e a

- $\quad$ situação final - referencia uma transformação ao considerar a situação inicial.

Esta operação orientou-se pelo princípio da narrativa quando explica que as pausas não se fazem em função das frases, mas em função de macroproposições mais amplas, de desmembramentos de acontecimentos.

Conforme explica Spink (1999) esse diálogo, entendido à luz de categorias e informações contextuais variadas, mostra a interpretação como um elemento intrínseco ao processo de pesquisa. Dessa forma, iniciando com as categorias teóricas, esse processo levou, num segundo momento, à redefinição das categorias analíticas em torno das cinco temáticas de composição do corpus, conforme o quadro 3:

Quadro 3 - Esquema narrativo de composição do corpus

\begin{tabular}{cc}
\hline SEQÜENCIA NARRATIVA & TEMAS DE COMPOSIÇÃO DO CORPUS \\
\hline Situação inicial & Formação e dimensões da comunidade \\
\hline Nó desencadeador & Objetivos da comunidade \\
\hline Ação & A organização e a participação dos membros \\
\hline Desenlace & O desenvolvimento e o relacionamento \\
\hline Situação final & Os resultados e o apoio do banco \\
\hline
\end{tabular}

Fonte: elaborado pelos autores

Portanto, a experiência da leitura está baseada numa estratégia de comunicação que enfatiza a enunciação narrativa a partir da ligação entre o mundo da história narrada/o mundo das ações dos leitores e/ou dos ouvintes e o investimento comum à comunidade.

Feita essa breve contextualização sobre o tópico de interesse da comunidade e tendo buscado referências na literatura pertinente ao tema, apresentamos as histórias ouvidas, as quais foram analisadas segundo a composição narrativa descrita anteriormente. 


\section{Segurança da informação: tópico de interesse da comunidade de prática}

Segurança da informação é a proteção contra ameaças às informações, visando assegurar a continuidade do negócio, minimizando danos comerciais e maximizando o retorno de possibilidades e investimentos (ISO, 2000). A Política de Segurança da Informação (PSI) é estabelecida por uma série de controles, diretrizes e normas cujo objetivo é resguardar as informações dos clientes e da empresa, controlando o risco de que sejam reveladas ou alteradas por pessoas não autorizadas.

Com a revolução dos computadores pessoais e dos sistemas de computação multiprocessados e, mais recentemente, com a ligação das redes de computadores das organizações à internet ou a redes de computadores de parceiros de negócios, a gestão da segurança tornou-se uma tarefa muito mais essencial e complexa. Os princípios tradicionais de segurança da informação - "confidencialidade", integridade e disponibilidade - tornaram-se restritos. As organizações vêm sendo, de certa forma, compelidas a disseminar e estimular, entre seus colaboradores, parceiros e aliados estratégicos, uma subcultura em que se considerem, também, responsabilidade, confiança e ética (DHILLON e BACKHOUSE, 2000).

Uma pesquisa desenvolvida no Brasil, com profissionais da área de tecnologia e segurança da informação de diversos segmentos de negócios, revelou dados não muito animadores relacionados ao tema (MÓDULO, 2002), dentre os quais destacam-se os seguintes:

- 77\% das empresas entrevistadas sofreram “ataques" (acessos não autorizados com o propósito de se apossar ou corromper dados) nos 12 meses anteriores à pesquisa;

- $35 \%$ das empresas reconhecem que tiveram perdas financeiras. Porém, $56 \%$ delas não conseguiram calcular os prejuízos causados pelos problemas com segurança da informação;

- $78 \%$ dos entrevistados acreditam que surgirão maiores problemas relacionados à segurança da informação;

- a falta de consciência por parte dos executivos (45\%) foi apontada como o principal obstáculo (23\%) para implantar procedimentos de segurança nas corporações;

- a área de tecnologia ainda é a responsável pela segurança da informação em $49 \%$ das empresas participantes da pesquisa. Em seguida, vem a área de security office com $25 \%$;

- apenas $60 \%$ das empresas fazem planejamento voltado para a segurança da informação.

- situação inicial: a formação e a dimensão da comunidade.

Considerando o primeiro estágio de desenvolvimento, chamado por Wenger (1999) de "potencial", a comunidade de prática surgiu da preocupação de algumas pessoas com que a segurança da informação fosse "levada um pouco mais a sério" no âmbito geral do banco. Essa constatação levou ao segundo estágio (a união), quando se procurou reunir, mediante "conversas de corredor" (ANTONELLO e RUAS, 2002), um grupo de pessoas de áreas distintas cujo conhecimento cobrisse dois importantes segmentos responsáveis pela segurança da informação na organização: tecnologia e auditoria.

A comunidade de prática foi criada há cerca de cinco anos, logo depois de um diagnóstico sobre segurança da informação feito por uma empresa de consultoria especializada contratada pelo banco. Esse trabalho havia gerado, entre outros produtos, a Política de Segurança da Informação do banco. Precisamente por sentir que a PSI "parecia fadada ao limbo", precisando de "gente mais focada" para executá-la, a princípio, seis pessoas começaram a se reunir, informalmente. Houve tentativas, ainda que frustradas, de formalização do grupo; isso porque a Política de Segurança da Informação previa a criação, nunca implementada, de um grupo responsável por mantê-la atualizada e por homologar normas de segurança. A composição desse grupo, ainda segundo essa política, seria de pessoas com perfil gerencial. Entretanto, a dificuldade formal de reunir pessoas do corpo diretivo do banco para discutir problemas técnicos contribuiu para que tudo não saísse do 
papel e a formação desse grupo que estabeleceria e sustentaria o dinamismo dessa política ficasse relegada a um plano secundário.

Segundo os níveis de participação definidos por Wenger (1999), essa lacuna foi sendo preenchida por algumas pessoas (grupo principal) que se apresentaram - e se aceitaram mutuamente - como voluntárias para o debate de questões de segurança da informação que criavam impasse no dia-a-dia dos negócios. Os assuntos e problemas pautados eram discutidos, chegava-se a um consenso e, até mesmo, eram estabelecidas algumas determinações sobre o que e como seria feito.

Os participantes que compuseram a comunidade de prática foram movidos pelo interesse direto e profissional no assunto sobre o qual liam e discutiam no cotidiano de suas atividades de consultoria técnica, auditoria ou gestão (WENGER e SNYDER, 2001). Os seis membros que vieram a constituir o núcleo da comunidade de prática eram profissionais que vinham construindo, de forma direta ou indireta, a história da segurança da informação no banco, desde os primórdios do processamento centralizado em mainframes (computadores de grande porte) até a "explosão" das redes de microcomputadores.

\section{Nó desencadeador: os objetivos da comunidade}

A comunidade de prática teve como "domínio de conhecimento" definir diretrizes ou orientações a respeito de segurança da informação, visando à implementação de uma segurança compatível com os serviços disponibilizados pelo Banco (WENGER et al, 2002).

Os integrantes da comunidade de prática eram originários, basicamente, de três áreas: a de formulação de estratégias de tecnologia, a de infra-estrutura e suporte de tecnologia e a de auditoria. Conforme Wenger (1999), no início do processo de desenvolvimento de uma comunidade, as pessoas buscam valor no engajamento em atividades de aprendizagem. Considerando essa premissa, desde o início houve a preocupação com que a participação fosse bastante heterogênea em termos de conhecimentos $\mathrm{e}$ competências. Participavam pessoas com visão eminentemente estratégica em segurança da informação e outras, com conhecimento técnico mais aprofundado do tema. Caracterizando a forma de participação definida por Wenger (1999) como "acesso passivo", em momentos específicos, a conversação se ampliava, também envolvendo os usuários de sistemas computadorizados, para discutir as necessidades e problemas relacionados à segurança da informação.

\section{Ação: a organização e a participação dos membros da comunidade}

No início da comunidade os encontros ocorriam conforme a demanda: quando surgia uma questão ou problema, a comunidade de prática se reunia de modo presencial. Em seguida, tentou-se uma periodicidade mensal para as reuniões, ainda que em épocas "mais turbulentas", os encontros acontecessem até quatro vezes por semana. Não, havia, porém, rigidez nessa periodicidade. "Se algum membro não podia participar, a comunidade não se juntava de modo presencial". Preocupados com a forma como os encontros estavam sendo conduzidos, os membros estipularam que, mesmo não tendo uma matéria específica de interesse, procurariam se encontrar a cada 15 dias para conversar, baseados, entretanto, numa pauta. Finalmente, as reuniões tornaram-se semanais.

Como "estratégia" para validar sua existência e a de algumas de suas deliberações, a comunidade de prática incluía três gestores: um de nível superior na hierarquia da empresa - o superintendente da área de tecnologia - e outros dois de segundo escalão - o gerente do departamento de formulação de estratégias de tecnologia e o gerente do departamento de infra-estrutura e suporte de tecnologia. Conforme observado por Lave e Wenger (1991), esses gestores raramente participavam das reuniões (participação periférica), mas tinham acesso às informações geradas nos encontros presenciais e on line. Wenger (1998) salientou que as comunidades de prática caracterizam contextos sociohistóricos, nos quais ocorre o aprendizado social, pela negociação de significados, da participação e da reificação. Nesse sentido, os problemas eram colocados em pauta e após uma série de rodadas de discussão se buscava o consenso para as decisões e resoluções finais. 
Quando não se chegava ao consenso, as pautas eram colocadas em votação. Quando os interesses e problemas não tinham a fundamentação necessária, a discussão não prosseguia antes de um processo de investigação e levantamento de dados (ROCHA, 2001).

Em relação aos mecanismos de confiança elaborados, "não havia guerra de vaidades, pois não se percebia a autoria da idéia; a idéia surgia das discussões e do trabalho do grupo" (BROWN e DUGUID, 2000). A participação nos encontros era livre, espontânea e intensa, influenciada pelo interesse no tema (WENGER e SNYDER, 2001). Era um momento em que as pessoas tentavam colocar em prática ou debater certas questões propostas na teoria, servindo como um fórum de disseminação de conhecimento e de busca da melhor solução possível para problemas trazidos à comunidade. Quanto a esse trecho da história, Wenger (1998) demonstra que o desenvolvimento da prática é menos uma questão de tempo e mais um problema de sustentação do engajamento na busca de um empreendimento mútuo para compartilhar um aprendizado significativo.

Além das reuniões presenciais, o grupo trocava informações por correio eletrônico e telefone - tanto que algumas questões eram discutidas e decididas através desses contatos virtuais -, sem contar o recurso à intranet do banco (TERRA e GORDON, 2002).

Em relação ao desenvolvimento de práticas, as deliberações disciplinares da comunidade passavam a compor a Política de Segurança da Informação ou normas de auditoria, tornando-se preceitos oficiais. Fora isso, as mensagens trocadas, os comentários e os itens de discussão eram passados para uma ata enviada a todos os membros. Segundo Wenger (2002), as pessoas se capacitam não só pela prática no desenvolvimento de um repertório, mas também compartilhando recursos que incorporam o conhecimento acumulado pela comunidade. Esse repertório fundamenta a futura aprendizagem.

A comunidade de prática se caracterizava pela participação e eqüidade na tomada de decisões. Não seguia uma organização hierárquica, mesmo considerando que um dos integrantes do seu núcleo exercia (na estrutura formal) uma função de gerência. Os membros acreditavam que a comunidade funcionava muito bem, exatamente por "não ter coordenação de grupo ou definidor de coisa alguma". O único papel atribuído por consenso a um dos membros era o de organizador das reuniões, encarregado de ordenar a pauta, convidar os integrantes e compor a ata no final dos encontros.

\section{Desenlace: o desenvolvimento da comunidade e o relacionamento com o restante da organização bancária}

Pouco a pouco, a comunidade de prática passou a ser requerida - sobretudo, pelas equipes de tecnologia da informação do banco - para discutir aspectos de segurança relacionados a serviços como os sistemas aplicativos, a arquitetura da rede de computadores e aqueles disponibilizados na internet. Quando se pretendia legitimar algumas ações referentes à gestão do banco, igualmente se recorria à comunidade, pelo reconhecimento da capacidade técnica de seus integrantes (TERRA e GORDON, 2002).

Contudo, a organização não considerava as opiniões e considerações da comunidade das quais divergisse, obstruindo a implementação de várias dessas recomendações, que, por seu caráter informal, não tinham poder normativo; ou seja, não havia a obrigatoriedade de serem acatadas.

Por outro lado, e em seu estágio de desenvolvimento mais ativo, essa mesma organização chegou a valer-se do nome da comunidade, como se esta fosse formalmente constituída, para advertir colaboradores que eventualmente descumpriam normas e diretrizes de segurança. Ou seja, "um reconhecimento tácito da competência técnica que a comunidade de prática instituía junto aos usuários de recursos tecnológicos". Por fim e, segundo Wenger (1999), considerando que o grande desafio para as organizações atuais é fortalecer o desenvolvimento das comunidades de prática dentro de suas estruturas formais e rígidas, houve um momento em que o banco cogitou a possibilidade de extinção da comunidade de prática. Esse foi um dos principais motivos para que seus integrantes apoiassem a idéia de formatar a estrutura formal da segurança no banco. 
Assim, a comunidade se ressente de várias deliberações importantes que não foram implementadas (McMASTER, 2000; TERRA e GORDON, 2002). Também se suscetibiliza com a falta de apoio e reconhecimento, demonstrada, por exemplo, com "a não indicação dos membros da comunidade de prática em programas de treinamento e formação específicos em segurança da informação". Os membros da comunidade de prática entendiam que a organização poderia fomentar iniciativas dessa natureza, adotando algumas ações, como o patrocínio de formação nas temáticas em discussão na comunidade, estímulo à participação de seus membros em estudos e projetos correlatos, convites a professores e consultores internos e externos ao banco para proferir palestras e seminários especializados, aquisição de recursos (como livros e subscrição de publicações técnicas) para instrumentar a comunidade, divulgação (na mídia interna) da existência da comunidade e de seus produtos e resultados.

Esses fragmentos da narração se coadunam com a discussão proposta por Wenger (1999) sobre o estímulo da organização formal às comunidades de aprendizagem pelo apoio aos processos de reflexão e ao compartilhamento de sua história como um recurso social para rápida aprendizagem.

Houve um momento em que a organização tentou utilizar a comunidade de prática para homologar determinadas ações com as quais os seus membros não concordavam. Isso gerou um conflito por conta do qual alguns integrantes desencadearam, junto aos demais, discussões visando ao desligamento da comunidade. A partir daí, devido à baixa motivação do grupo e, mais recentemente, pelas turbulências resultantes da mudança da alta administração do banco, as reuniões presenciais, que num primeiro momento se tornaram esparsas, acabaram cessando.

Naquele momento, o banco também estruturou uma unidade administrativa vinculada ao departamento de infra-estrutura e suporte de tecnologia, para cuidar de assuntos pertinentes à segurança. Tal iniciativa colidiu, em essência, com o disposto (e ainda vigente) em sua própria Política de Segurança da Informação. Afinal, "de conformidade com a Política, as homologações de normas e diretrizes de segurança deveriam ser de competência de um colegiado".

Depois dessa aparente dispersão, não houve consenso entre os integrantes quanto ao futuro da comunidade, (WENGER, 1999). Alguns achavam que ela - ou, pelo menos alguns de seus membros - continuaria organizados como órgão consultivo da nova unidade de segurança estruturada pelo banco; ou seja, "uma parte informal do grupo formal". Outros acreditavam que alguns integrantes se agrupariam de maneira formal, em torno da nova estrutura, perdendo, assim, a característica primordial e intrínseca de uma comunidade de prática, que é a informalidade (CAPRA, 2004). De certa forma, a comunidade sobrevive de forma virtual. "O grupo troca, eventualmente, algumas correspondências via correio eletrônico".

\section{Situação final: os resultados da comunidade e 0 apoio do banco}

Conforme salientou Allee (2000), os integrantes da comunidade de prática são unânimes quando aludem à contribuição que ela dá aos indivíduos, ao negócio da organização e à própria comunidade: "o pouco do que existe hoje definido em termos de segurança da informação dentro do banco se deve muito a esse grupo". São citados como exemplos, dentre outros, "a estrutura de segurança da internet, o controle de senhas, o sistema de controle de acesso a aplicativos e a implementação de uma série de ferramentas especializadas".

De modo subjacente, a comunidade de prática logrou "colocar em cena a disciplina segurança", mostrando que o tema permeia todos os níveis da organização e de cujo cotidiano deve fazer parte. Também de forma indireta, a ação da comunidade contribuiu para que a direção do banco decidisse pela criação de setor específico no organograma da empresa para pensar a segurança, conforme depoimentos dos participantes da comunidade: "não era onde, estruturalmente, a gente acha que deveria ser, mas, pelo menos, já apareceu na estrutura do banco algo oficial para se preocupar com a segurança". Ainda segundo Allee (2000) quando relata sobre os benefícios trazidos pela comunidade de prática aos seus membros, são mencionados 
a ampliação do conhecimento sobre o tema segurança da informação, pelo incentivo a seus integrantes para que se aprofundem nos estudos e pesquisas e ao autodesenvolvimento técnico e cognitivo; o respaldo tecnogerencial para a implementação de ações de segurança que, de modo isolado, um membro não conseguiria; e a ambiência favorável à troca de experiências e ao intercâmbio de informações de pessoas de áreas de conhecimento correlatas e em virtude de objetivos comuns.

Os integrantes da comunidade de prática também partilham o mesmo sentimento quanto ao sucesso dessa iniciativa, desconhecendo "dentro do banco outra atividade que tenha surgido assim, sem buscar nada, sem querer nada, sem estar atrás de cargo, sem estar atrás de coisa nenhuma, querer resolver um problema e acabar ganhando o reconhecimento que o grupo acabou ganhando". Esse êxito pode ser percebido quando se compara o que havia antes na empresa com o que se tem agora, em termos de segurança da informação. No entanto, para McMaster (2000) e Terra e Gordon (2002), no que diz respeito ao comprometimento, a avaliação do potencial e evolução dessas comunidades por parte das lideranças nas organizações poderia ter sido melhor sucedida se houvesse "uma 'certificação' (da comunidade), que seria a validação desse modelo de forma institucional".

\section{Conclusões}

A aprendizagem organizacional vem sendo estudada por pesquisadores de diferentes áreas do conhecimento, preocupados em entender o comportamento das organizações e como estas aprendem e utilizam o aprendizado para melhorar seus processos de gestão.

Os processos formais desenhados pelas organizações não dão conta do que acontece na prática, na atividade diária do trabalhador, na qual a espontaneidade na busca de soluções para os problemas é fonte promissora para o aprendizado organizacional. Assim, a prática ganha importância, pois é fundamental para o entendimento do trabalho e como fonte de inovação. Essas práticas em comum permitem às pessoas formarem redes sociais ao longo das quais o conhecimento sobre aquela prática, construído através de "atos de participação", pode tanto passar rapidamente como ser assimilado rapidamente (BROWN e DUGUID, 2000).

Nas comunidades de prática, os membros compartilham histórias, casos e soluções que passam de colaborador a colaborador formando uma rede, na qual o conhecimento é integrado e construído coletivamente.

Este artigo investigou uma comunidade de prática focada no tópico segurança da informação de um banco federal, a partir da narração das histórias e experiências dos próprios atores envolvidos. Foi adotada a abordagem qualitativa para o desenvolvimento metodológico da pesquisa a partir da articulação de um instrumento de análise da narrativa.

Considerando que todo texto narrativo resulta de uma atividade criativa que opera uma "redescrição" da ação humana, foram revelados importantes eventos e características do grupo estudado - que distinguiram a comunidade de prática -, dentre os quais: a criação de um sentido de empreendimento comum, o desenvolvimento de um repertório compartido de conceitos, ferramentas, linguagens e histórias e a construção do conhecimento social, mais que o mero compartilhamento de informações. Contudo, deve ser registrado que na comunidade estudada não foi constatada a ampla diversidade de papéis prescritos no referencial teórico, identificando-se apenas aqueles de bibliotecário e perito. Foi observado ainda que para os integrantes dessa comunidade, seu bom funcionamento decorria, em grande parte, de não haver uma coordenação outorgada. Também foi constatado que apesar da virtualidade favorecida pela tecnologia da informação, as reuniões presenciais se tornaram essenciais para manter o sentido de nexo e pertença. 
Por fim, verificou-se que a comunidade de prática cumprira quatro estágios de desenvolvimento estabelecidos por Wenger (1999): "potencial", "união", "madura" e "ativa". No momento em que era feita a pesquisa, vivenciava o estágio "dispersão".

Haja vista o conflito estabelecido na história da comunidade de prática examinada, sugere-se que a empresa garanta apoio à dispersão da comunidade, pelo reconhecimento de seus produtos e resultados, quanto pela preservação dos artefatos e da memória construídos por seus integrantes.

Por último, o caso levanta questões que precisam ser refletidas no estudo de outras comunidades. Dentre esses temas estão as pesquisas sobre gestão dos conflitos e práticas negociais dos interesses divergentes entre comunidade e empresa, investigações sobre as práticas que surgem dos processos formais e como essas práticas contribuem para a aprendizagem organizacional. 


\section{Referências bibliográficas}

ADAM, J-M.; REVAZ, F. A Análise da narrativa. Lisboa: Gradiva, 1997.

ALBERTI, V. História oral: a experiência do Cpdoc. Rio de Janeiro: Cpdoc/FGV, 1989.

ALLEE, V. Knowledge networks e communities of practice. Journal of the Organization Development Network, v.32, n.4, 2000. Disponível em: <http://www.odnetwork.org/odponline/vol32n4/knowledgenets.html>. Acesso em: 16 fev.. 2004.

ANTONELLO, C. S.; RUAS, R. Formação gerencial: pós- graduação lato sensu e o papel das comunidades de prática. In: ENCONTRO DA ASSOCIACAO NACIONAL DOS PROGRAMAS DE PÓS-GRADUAÇÃO (Enanpad), 26., 2002, Salvador. Anais... Salvador: Anpad, 2002.

BROWN, J. S.; DUGUID, P. The social life of information. Harvard Businesses Scholl Press: Boston, Massachusetts, 2000.

CAPRA, F.; Complexity and management. Disponível em: <http://www.ecoagencia.com.Br/fsm4/fsm/00000068.htm>. Acesso em: 16 fev. 2004.

DHILLON, G.; BACKHOUSE, J. Information system security management in the new millennium. Communications of the ACM, v.43, n.7, p.25-128, July 2000.

EASTERBY - SM ITH, M; ARAÚJ O, L. Aprendizagem organizacional: oportunidades e debates atuais. In: EASTERBY - SM ITH, M; BURGOYNE, J.; ARAÚJ O, L. (Org.). Aprendizagem organizacional e organização de aprendizagem. Desenvolvimento na teoria e na prática. São Paulo: Atlas, 2001

INTERNATIONAL ORGANIZATIONAL FOR STANDARDIZATION. ISO/IEC 17799:2000: Code of practice for information security management. New Jersey, 2000.

LAVE, J.; WENGER, E. Situated learning: legitimate peripheral participation. Cambridge: Cambridge University Press, 1991.

M CMASTER, M. Communities of practice: an introduction (2000). Disponível em: <http://www.co-i-l.com/coil/knowledgegarden/cop/mmintro.shtml>. Acesso em: 16 fev. 2004.

MÓDULO SECURITY SOLUTIONS. Pesquisa Nacional de Segurança da Informação (2002). Disponível em: <http://www.modulo.com.br/index.jsp>. Acesso em: 16 fev. 2004.

ROCHA, C. T. C. A informação via artefatos tecnológico-computacionais nas comunidades de prática: os faróis do saber de Curitiba. 2001. 180 f. Dissertação (Mestrado) - Centro Federal de Educação Tecnológica do Paraná. Curitiba. 2001.

ROSENTHAL, G. A estrutura e a gestalt das autobiografias e suas conseqüências metodológicas. In: FERREIRA, M. M; AMADO, J. Usos e abusos da história oral. Rio de Janeiro: FGV, 2000.

SIMS, D. Aprendizagem organizacional como o desenvolvimento de histórias: cânones, apócrifos e mitos piedosos. In: EASTERBYSMITH, M.; BURGOYNE, J. E; ARAÚJ O, L. Aprendizagem organizacional e organização de aprendizagem: desenvolvimento na teoria e na prática. São Paulo: Atlas, 2001.

SPINK, M. J. Práticas discursivas e produção de sentidos no cotidiano. São Paulo: Cortez, 1999.

TERRA, J. C. C; GORDON, C. Portais corporativos: a revolução na gestão do conhecimento. São Paulo: Negócio Editora, 2002.

WENGER, E. C. Communities of practice: learning, meaning, and identity. Cambridge: University Press, 1998.

. Communities of practice: learning as a social system. Presented in Toronto, Apr. 1999. Unpublished paper.

; SNYDER, W. M. Comunidades de prática: a fronteira organizacional. In: HARVARD BUSINESS REVIEW (Org.). Aprendizagem organizacional. Tradução Cássia Maria Nasser. Rio de Janeiro: Campus, 2001

YIN, R. K. Case study research: design and methods. 2.ed. Newburry Park: Sage Publications, 1994. 